\title{
An Empirical Test for Parities between Metal Prices at the LME
}

\author{
Philip Hans Franses \\ Paul Kofman
}

\section{INTRODUCTION}

$\mathrm{S}$ everal studies on primary commodities assume or suggest the presence of a temporal equilibrium relationship, or a parity, between their prices. For example Pindyck and Rotemberg (1988) and Ramanujam and Vines (1988) suggest that the co-movement of prices of largely unrelated raw materials are based upon certain macroeconomic events. Ma (1985) investigates trading rules derived from temporal equilibria between gold and silver prices. Ma discusses the concept of an equilibrium parity between prices over both the long- and short-run. The main argument is that similar factors affect the demands of these commodities due to the close substitutability in investors' portfolios. Prices can wander around this parity but are constantly driven back to it.

It is important to make a distinction between a stock parity and a flow parity because the first reflects the known resources of the commodities, and the latter concerns short-term flow supplies. As a consequence, prices may not only converge in the long-run to a fixed stock parity, but also move toward sequences of short-run flow equilibria. Ma and Soenen (1988) investigate the persistence of the flow parities in the futures market. Although transaction costs are likely to eliminate arbitrage profits from spot trading, in the case of futures trading, such profits may emerge because of lower costs. Ma and Soenen (1988) also present a trading strategy based on the observation of underpriced or overpriced relative prices given a flow parity.

This article focuses on an empirical test for the presence of flow parities. Given that futures prices are likely to be nonstationary, i.e., they fluctuate without a constant mean and with increasing variance, many standard statistical techniques cannot be used because they assume stationarity. One approach to investigating

The authors would like to thank Chris Gilbert; Marius Ooms; Jean-Marie Viaene; seminar participants at the Universities of Tilburg, Groningen, Leuven, and London; participants at the Fifth Symposium on Money, Banking, Finance, and Insurance in Karlsruhe (December 1990); and two anonymous reviewers for their helpful comments and constructive suggestions. The authors also thank Bernard Bot for providing and checking the data.

Philip Hans Franses is affiliated with the Econometric Institute and Tinbergen Institute, Erasmus University, Rotterdam.

\section{Paul Kofman is affiliated with the International Economics Department and} Tinbergen Institute, Erasmus University, Rotterdam.

The Journal of Futures Markets, Vol. 11, No. 6, 729-736 (1991)

(C) 1991 by John Wiley \& Sons, Inc.

CCC 0270-7314/91/060729-08\$04.00 
equilibrium relationships between nonstationary variables is the cointegration method developed in Johansen $(1988,1989)$. This method is particularly appropriate for this study because it provides test statistics for the number of flow parities and for the relationships as well. Moreover, an additional advantage over the procedure applied in Granger and Escribano (1988) is that no statements need to be made concerning exogeneity of prices. This study applies this cointegration method to test for parities between futures prices of five metals traded at the London Metal Exchange (LME).

\section{DATA}

There are various reasons for applying an empirical test for price parities to the LME. Traders in primary commodities are usually confronted with widely dispersed information sources. Production and consumption take place at various locations all over the world. Given such scattered information, it seems easier to follow the price behavior of somehow connected assets, such as those at the LME, than it is to follow divergent assets' price movements. Furthermore, the LME is not only a forward market but also the center for physical spot trade in metals. Thus, most rele $\%$.nt and available information is pooled at one reasonably closed market. This makes: this market attractive for investors with limited resources for costly information gathering.

This study focuses on the behavior, in 1981, of five nonferrous metals: aluminium, copper, lead, nickel, and zinc. Tin is excluded because the tin market suffered from intervention previous to its collapse in 1985. Already, in 1981, its price series show/s little variation which might disturb potential parity relationships. Silver is not considered because its trade is supposed to be more closely related to the London g,old futures than to the nonferrous metals. The series are obtained from Reuter's and amount to 251 daily forward price quotations from January 5, 1981 through December 31, 1981. Quotations are denominated in pounds sterling per metric tonne, and reflect settlement prices at market closing. Logarithmic values are used to ensure that the first differences of the series represent the returns. The graphs of the five series in Figure 1 clearly show similarities in the data patterns; and, hence, there is some visual evidence for the presence of one or more price parities.

The high trading volume and continuity in production of the considered commodities may avoid some common data irregularities like overlap in series and harvest effects. As noted in Gross (1988), the LME quotes forward prices, implying that the data are not overlapping as in the case of futures contracts with fixed delivery dates. The ongoing 3-month forward quotations make the LME contract better suited for production hedging purposes than a fixed delivery month futures contract would. This may account for the relatively high score of $15 \%$ of actual settlement of contracts (see Gibson-Jarvie, 1988). However, this still leaves $85 \%$ of all forward contracts needing to be reversed before delivery date. This is an important notion because it allows comparison of subsequent forward prices instead of forward versus future spot prices to evaluate returns on trading.

\section{COINTEGGRATION ANALYSIS}

Cointegration analysis examines the existence of stationary relationships between nonstationary variables (see e.g., Engle and Granger, 1987). It investigates whether variables, which fluctuate without a constant mean and with increasing variance, 


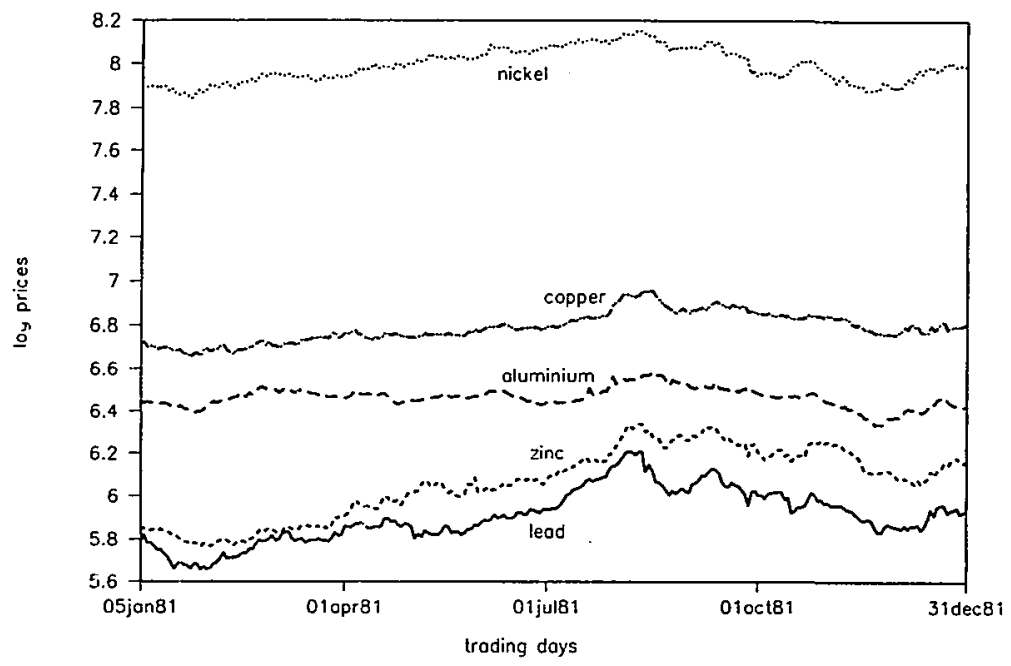

Figure 1

Metal prices at the LME.

are tied together in an equilibrium relationship. Such a cointegration relationship, which may be implied by economic theory, consists of a linear combination of the variables.

A check for the property of individually nonstationary variables consists of finding out whether the sample autocorrelations of the variables only die out slowly at high lags. From Table I, it can be seen that this applies to all series, although the evidence for the price of aluminium is not overwhelming. A formal test for nonstationarity, or for the presence of a unit root, is given by the well-known DickeyFuller procedure. The presence of a linear deterministic trend in the 1-year sample

Table I

CHARACTERISTICS OF THE UNIVARIATE SERIES

\begin{tabular}{|c|c|c|c|c|c|c|c|c|}
\hline$P_{i}^{*}$ & Mean & $\mathbf{S D}^{\mathbf{b}}$ & $r_{1}{ }^{c}$ & $r_{5}$ & $r_{10}$ & $r_{15}$ & $r_{20}$ & (A)DF \\
\hline$P_{a t}$ & 6.466 & 0.046 & 0.968 & 0.844 & 0.662 & 0.436 & 0.237 & $-1.845(1)$ \\
\hline$P_{\mathrm{co}}$ & 6.790 & 0.069 & 0.987 & 0.927 & 0.845 & 0.757 & 0.688 & $-1.385(1)$ \\
\hline$P_{l e}$ & 5.906 & 0.126 & 0.987 & 0.930 & 0.831 & 0.735 & 0.651 & $-1.499(3)$ \\
\hline$P_{n i}$ & 7.995 & 0.077 & 0.983 & 0.916 & 0.815 & 0.713 & 0.634 & $-1.802(4)$ \\
\hline$P_{z i}$ & 6.061 & 0.166 & 0.991 & 0.949 & 0.894 & 0.839 & 0.780 & $-1.356(4)$ \\
\hline
\end{tabular}

${ }^{a}$ The variables are measured in natural logarithms. The $P_{i}$ denote the prices of aluminium, copper, lead, nickel, and zinc, respectively.

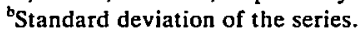

'Estimated autocorrelation at lags $1,5,10,15$, and 20. The estimated standard error is 0.063 .

"Augmented Dickey-Fuller test statistic for unit roots. This test is based on the " $t$ "-value of $\delta$ in $\Delta P_{t}=\gamma_{0}+\delta P_{t}+\sum_{j=1}^{k} \gamma_{j} \Delta P_{t-k}$. The value of $k$ is determined empirically and is given in parentheses. The $5 \%$ critical value is -2.90 . 
seems unlikely; hence, the test regression includes only a constant term. The results in the final column of Table I suggest that the hypothesis of five random walks cannot be rejected. The sample autocorrelations of the first differenced series do not suggest thit these transformed series are nonstationary, so the returns are stationary variables.

One approach to cointegration, in which it is possible to test for the number of cointegration relationships, is given by Johansen $(1988,1989)$. A related financial application and a concise survey is found in Baillie and Bollerslev (1989). For the present purpose, it suffices to highlight only some of the major steps. Assume that the vector containing the five nonstationary price variables $X_{t}$ can be modeled with an autoreg,ressive time series model of $\operatorname{order} p$, or

$$
X_{t}=\mu_{i}+\Pi_{1} X_{t-1}+\ldots \ldots+\Pi_{p} X_{t-p}+\varepsilon_{t}
$$

where $\varepsilon_{r}$ denotes an independently and identically distributed zero mean process with covariance matrix $\Omega$. It is convenient to rewrite Eq. (1) as

$$
\Delta X_{t}=\mu_{t}+\Gamma_{1} \Delta X_{t-1}+\ldots+\Gamma_{p-1} \Delta X_{t-p+1}+\Pi \tilde{\Lambda}_{t-p}+\tilde{c}_{t},
$$

where $\Delta$ denotes the first diffe ience operator. This equation is a so-called error correction model. The parameter matrices are now given by

$$
\Gamma_{i}=-I+\Pi_{1}+\ldots+\Pi_{i}
$$

and

$$
\Pi=-\left(I-\Pi_{1}-\ldots-\Pi_{p}\right),
$$

for $i=1, \ldots, p-1$. If rank $r$ of II is: $0<r<5$, then one has encountered $r$ cointegration relationships, or $5-r$ multivariate unit roots in the vector process $X_{i}$. Now the matrix $\pi$ can be written as $\alpha \beta^{\prime}$, where $\alpha$ and $\beta$ are $(5 \times r)$ matrices. The cointegration vectors, $\beta$, have the property that $\beta^{\prime} X_{t}$ is :stationary, and the matrix $\alpha$ contains the dynamic adjustment coefficients. When $r=5$, there are no unit roots at all, so the components of $X_{t}$ are stationary: and Eq. (1) applies. When $r=0$, there are no common unit roots and Eq. (2) reduces to a vector autoregressive: model for the variables in first differences. Hence, note that testing for cointegration implies, in fact, testing for integration of the individual series. In the case of cointegration, it is clear that the latter model is misspecified because it lacks the error correction term $\beta^{\prime} X_{t-p}$.

In Johansen $(1988,1989)$, a method is developed to test for the value of $r$. The test statistic is based on the eigenvalues $\lambda_{i}\left[\lambda_{i} \geq \lambda_{i+1}\right]$ of the canorical correlation matrix between $\Delta X_{t}$ and $X_{t-p}$ after correction for $\Delta X_{t-1}$ through $\Delta X_{t-p+1}$ (Johansen, 1988), and additionally, for eventual trend and/or mean (Johansen, 1989). Ir. this application, however, only the absence of a linear deterministic trend is assumed. Hence, the modified test procedure (Johansen, 1989, p. 8), provides that one calculates $p+1$ eigenvalues, one of which equals zero and will not be used for the test statistic below. Loosely speaking, the test procedure boils down tc the choice of the $r$ linear combinations of the elements of $X$, that have the largest $f$ artial correlations with $\Delta X$. The likelihood ratio test statistic for the null hypothesis $r \leq q$, where $q=0,1, \ldots, 4$, is

$$
L=-n \sum_{i=r+1}^{5} \ln \left(1-\lambda_{i}\right)
$$


for which the appropriate critical values used in this study are tabulated in Johansen (1989, Table T.III).

The identification of the adequate order $p$ of the model in Eq. (1) is of considerable importance. Simulation evidence and practical experience with cointegration techniques indicate that dynamic misspecification may affect the outcome of the test procedure in the sense that, in general, too large a model reduces the power while too small a model increases its size. The intuitive reasoning of the latter is that insufficient removal of temporal correlation may positively influence the partial correlations between $\beta^{\prime} X_{t}$ and $\Delta X_{t}$. A convenient model selection procedure is to pick the smallest model without temporal correlation in the estimated residuals. Note that this concerns correlation within as well as between the equations. In this case the suitable model is Eq. (1) with $p=2$. The eigenvalues of the relevant canonical correlation matrix are displayed in Table II. The results for the test statistic $L$ imply that the presence of one cointegration relationship cannot be rejected, and it is given by

$$
0.086 P_{a l}-0.339 P_{c o}+0.109 P_{l e}-0.023 P_{n i}+0.059 P_{z i}+0.9283
$$

The estimation results, i.e., the estimated $\Gamma_{1}, \Pi, \Omega$, and $\mu$, given the presence of one cointegration relationship, are displayed in the second part of Table II. Figure 2 contains the graph of the parity, and it seems to be stationary. The adjustment coefficients $\alpha_{i}$, when multiplied by $10^{-4}$, are $-0.027,0.126,0.022,-0.003$, and 0.044 , respectively. The vector $\alpha$ reflects the adjustment effects of the prices to disequilibrium errors. Although these values are small it can be seen that the speed of adjustment to the equilibrium state is highest for the price of copper, and lowest for the price of nickel. The price of copper rapidly reacts to disequilibrium errors and in this respect, may be viewed as being less exogenous than, e.g., the price of nickel. In principle, it is now possible to formally test which elements of $\alpha$ can be set equal to zero, and also whether there are valid restrictions on the elements of $\beta$.

Table II

COINTEGRATION AND ESTIMATION RESULTS

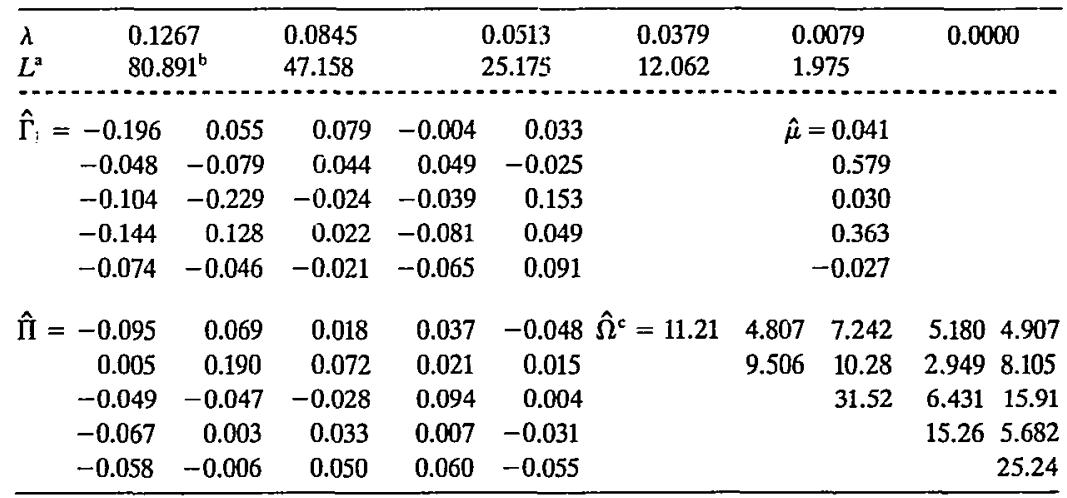

${ }^{2}$ The $5 \%$ critical values are, respectively: $75.328,53.347,35.068,20.168$, and 9.094 . The number of observations is 249 .

'Significant at the $5 \%$ level.

These values are multiplied by $10^{5}$. 


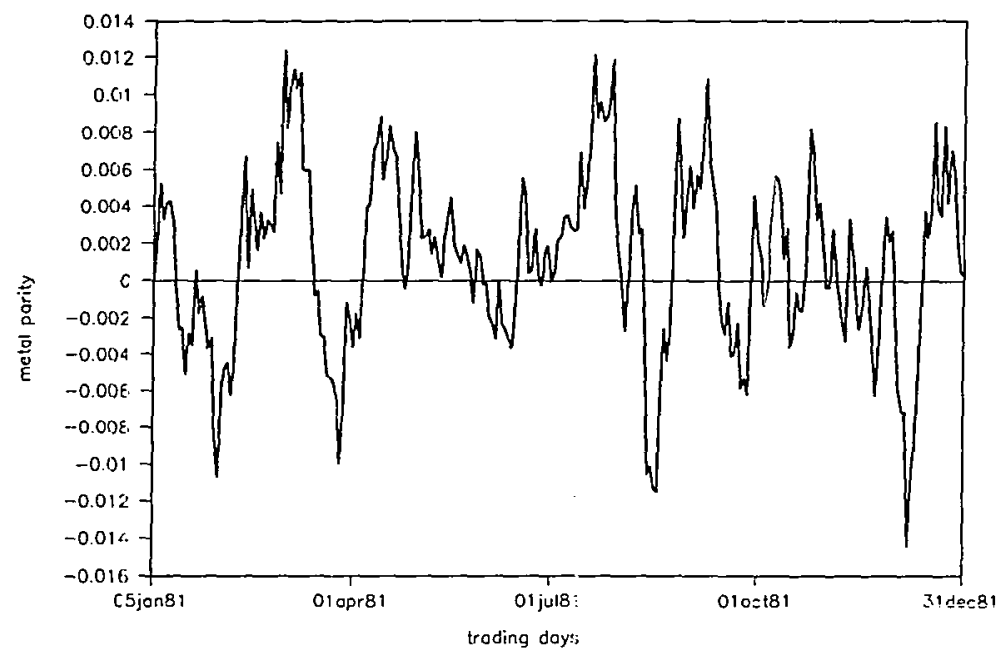

Figure 2

The cointegration relationship.

With the: equilibrium relationship and the adjustment coefficients, one can try to disentangle relationships between pairs of variables assuming ceteris paribus conditions. For example, when the price of copper rises and all other prices remain equal, it follows that the equilibrium error is negative, and this produces a positive effect on the price of aluminium via the $\alpha$. A similar argument applies to a positive change in the price of zinc and its positive effect on the price: of lead two days later. Hence, the error correction term implies some forecastab:lity of the considered metal prices; although, in the present case, any gain is rather small given the values of $\alpha$.

\section{DISCUSSION AND CONCLUDING REMARKS}

This article illustrates how a cointegration method can be usefully implemented when considering equilibrium relationships among commodity prices and how it provides an empirical test for price parities. It is found that one cointegration relationship, or parity, exists between five forward metal prices on the LME over 251 trading days in 1981. Figure 2 illustrates that the kurtosis of the cointegration relationship may come close to the normality value, while those of the individual returns may not. Unreported calculations show that this is the case indeed.

A potential limitation to all parity st 1 dies is the inconclusiveness in determining the optimal sample length. In the gold/silver case in $\mathrm{Ma}(1985, \mathrm{p} .579)$ some data are given on the long-term stock parity. This parity reflects the relative scarcity of the precious metals. The historical facts show that this gold/silver parity can change considerably over periods of time. Depletion of known resources and exploitation/ exploration of new and unknown resources can alter the parity. This can be important for short-term flow parities, for they inevitably move toward stock parities. 
Since stock parities seem to exhibit a jump pattern, it is important to test flow parities in between these jumps. It is clear that the same argument applies to other exhaustible resources like the nonferrous metals.

One might argue that the price parity and the corresponding adjustment coefficients used here reflect whether some metals have a substitutive character, and whether others may be viewed as complementary. Although the error correction model implies forecastibility of the prices, it may be troublesome to trace the exact effects of contemporaneous changes in the prices on the prices within two days. Furthermore, the size and length of the data set may not give rise to defendable assumptions on (in)elastic supply or demand, which are prerequisites for predictions from economic theory. On the other hand, in case such assumptions can be made, and in case, e.g., substitutability implies a parity between prices, then the cointegration method may be useful to empirically establish this relationship. Within this approach it is not necessary to assume a moving average process for the parity to ensure its stability (Ma, 1985). Cointegration automatically implies stationary equilibria.

Through measurement of market errors, i.e., actual parity minus flow equilibrium parity, it is possible to investigate whether a commodity is relatively overor underpriced. Ma (1985, p. 580) notes the importance of the possibility to identify changes in direction of the flow parity. The dynamic adjustment coefficients in front of the error correction term used in this study tell in what direction the price of each commodity will move to reestablish the parity relationship after some disturbance. The adjustment of prices takes place within two trading days, which may be viewed as a short period.

The relationship between the existence of a parity and the efficient market hypothesis (EMH) is explained. Granger and Escribano (1988) conclude that the existence of cointegration necessarily leads to the rejection of the EMH. A lot of confusion surrounds empirical research on this topic due to the fact that different definitions of efficiency coexist (cf. Gross, 1988). Ma and Soenen (1988) reject weak-form market efficiency where there are positive excess returns. If the definition of EMH implies that the random walk model is the best forecasting scheme, then the EMH can be rejected for the LME. The sensible user of an error correction model may benefit from some forecastability of metal prices. The conclusion in MacDonald and Taylor (1989) that the rejection of the EMH for metals is possibly due to irrationality of traders might then need a revision.

\section{Bibliography}

Ballie, R.T., and Bollerslev, T. (1989): "Common Stochastic Trends in a System of Exchange Rates," Journal of Finance, 44:167-181.

Engle, R.F., and Granger, C.W.J. (1987): "Co-integration and Error Correction: Representation, Estimation and Testing," Econometrica, 55:251-276.

Gilsson-Jarvie, R. (1988): The London Metal Exchange: A Commodity Market (3rd ed), Camtıridge, UK: Woodhead-Faulkner.

Gringer, C.W.J. and Escribano, A. (1988): "The Long-run Relationship Between Prices From an Efficient Market: The Case of Gold and Silver," Mimeograph, University of California, San Diego.

Gross, M. (198:3): “A Semi-Strong Test of the Efficiency of the Aluminum and Copper Markets at the LME," Journal of Futures Markets, 8:67-77. 
Johansen, S. (1988): "Statistical Analysis of Cointegration Vectors," Journal of Economic Dynamics and Control, 12:231-254.

Johansen, S. (1989): Likelihood Based Inference on Cointegration. Theory and Applications, Bologna:Centro Interuniversitario di Econometria.

Ma, C. K. (1985): "Spreading Between the Gold and Silver Markets: Is There a Parity?" Journal of Fulures Markets, 5:579-594.

Ma, C. K., and Soenen, L.A. (1988): "Arbitrage Opportunities in Metal Futures Markets," Journal of Futures Markets, 8:199-209.

MacDonald, R., and Taylor, M.P. (1989): "Testing Rational Expectations and Efficiency in the London Metal Exchange," Oxford Bulletin of Economics and Statistics, 50:41-52.

Pindyck, R.S., and Rotemberg, J. J. (1990): "The Excess Co-movement of Commodity Prices," Economic Journal, 100:1173-1189.

Ramanujam, P., and Vines, D. (1988): "Commodity Prices, Financial Markets and World Income: A 'Structural Rational Expectations Model," Working Paper, University of Glasgow, Glasgow. 